Article

\title{
Simulation of Light Distribution in Gamma Irradiated UHMWPE Using Monte Carlo Model for Light (MCML) Transport in Turbid Media: Analysis for Industrial Scale Biomaterial Modifications
}

\author{
Ali Rizwan ${ }^{1}\left(\mathbb{D}\right.$, Muhammad Saleem $^{2}$ (D), Suhail H. Serbaya ${ }^{1} \mathbb{D}$, Hemaid Alsulami ${ }^{1}$, Aqsa Ghazal ${ }^{3}$ \\ and Malik Sajjad Mehmood ${ }^{3, *}$ (D)
}

1 Department of Industrial Engineering, Faculty of Engineering, King Abdulaziz University, Jeddah 21589, Saudi Arabia; arkhan71@kau.edu.sa (A.R.); sserbaya@kau.edu.sa (S.H.S.); healsulami@kau.edu.sa (H.A.)

2 Department of Industrial Engineering, Faculty of Engineering-Rabigh, King Abdulaziz University, Jeddah 21589, Saudi Arabia; msaleim1@kau.edu.sa

3 Department of Basic Sciences, University of Engineering and Technology, Taxila 47050, Pakistan; aqsaghazal06@gmail.com

* Correspondence: msajjad.82@gmail.com

check for updates

Citation: Rizwan, A.; Saleem, M.; Serbaya, S.H.; Alsulami, H.; Ghazal, A.; Mehmood, M.S. Simulation of Light Distribution in Gamma Irradiated UHMWPE Using Monte Carlo Model for Light (MCML) Transport in Turbid Media: Analysis for Industrial Scale Biomaterial Modifications. Polymers 2021, 13, 3039. https://doi.org/10.3390/ polym13183039

Academic Editors: Amor M. Abdelkader and Ilaria Armentano

Received: 14 August 2021

Accepted: 6 September 2021

Published: 9 September 2021

Publisher's Note: MDPI stays neutral with regard to jurisdictional claims in published maps and institutional affiliations.

Copyright: (c) 2021 by the authors. Licensee MDPI, Basel, Switzerland. This article is an open access article distributed under the terms and conditions of the Creative Commons Attribution (CC BY) license (https:/ / creativecommons.org/licenses/by/ $4.0 /)$.

\begin{abstract}
Background: This study investigated the miscibility of carbon-based fillers within industrial scale polymers for the preparation of superior quality polymer composites. It focuses on finding the light distribution in gamma irradiated ultra-high molecular weight polyethylene (UHMWPE). (2) Methods: The Kubleka-Munk model (KMM) was used to extract the optical properties, i.e., absorption coefficients $\left(\mu_{\mathrm{a}}\right)$ and scattering coefficients $\left(\mu_{\mathrm{s}}\right)$. Samples amounting to $30 \mathrm{kGy}$ and $100 \mathrm{kGy}$ of irradiated (in the open air) UHMWPE from $630 \mathrm{~nm}$ to $800 \mathrm{~nm}$ were used for this purpose. Moreover, theoretical validation of experimental results was performed while using extracted optical properties as inputs for the Monte Carlo model of light transport (MCML) code. (3) Conclusions: The investigations revealed that there was a significant decrease in absorption and scattering coefficient $\left(\mu_{\mathrm{a}} \& \mu_{\mathrm{s}}\right)$ values with irradiation, and $30 \mathrm{kGy}$ irradiated samples suffered more compared to $100 \mathrm{kGy}$ irradiated samples. Furthermore, the simulation of light transport for $800 \mathrm{~nm}$ showed an increase in penetration depth for UHMWPE after gamma irradiation. The decrease in dimensionless transport albedo $\frac{\mu_{\mathrm{s}}}{\left(\mu_{\mathrm{a}}+\mu_{\mathrm{s}}\right)}$ from 0.95 to 0.93 was considered responsible for this increase in photon absorption per unit area with irradiation. The report results are of particular importance when considering the light radiation (from $600 \mathrm{~nm}$ to $899 \mathrm{~nm}$ ) for polyethylene modification and/or stabilization via enhancing the polyethylene chain mobility.
\end{abstract}

Keywords: UHMWPE; chain mobility; photon distribution; Kubleka-Munk model; Monte Carlo simulation; gamma irradiations

\section{Introduction}

In recent decades, industrial applications of polymers and polymer composites have seen an exponential rise in different areas of our life, including pharmaceutical packaging, consumer goods, medical devices, food and cosmetic packaging, etc. Nowadays, the medical devices used for implant replacement are mostly fabricated with ultra-high molecular weight polyethylene (UHMWPE) and/or its carbon-based composites [1-3]. UHMWPE is the material of choice for orthopedic industrial applications and medical devices that are made of this industrial scale polymeric biomaterial are usually treated with high energy radiation such as gamma, e-beams, or X-rays for sterilization [4-11]. However, treating UHMWPE with high energy radiation also generates free radicals that are responsible for its degradation, thus limiting the service life of the UHMWPE-based medical devices. 
To quench these free radicals, different methodologies including post-irradiation melting, post-irradiation annealing and the inclusion of biocompatible antioxidants are in practice. Although the aforementioned methodologies work well to some extent, serious constraints exist for each method. Therefore, continuous efforts are in progress to figure out the best alternative for sterilization and stabilizing UHMWPE. In this regard, the concept of treating UHMWPE with light $[12,13]$ of suitable wavelength and/or energy seems to be appealing as it has the potential to address the harms associated with the aforementioned methods. Moreover, the non-ionizing nature of light also reduces the health risk for workers associated with the radiation sterilization industry of medical products. However, when using light to modify, sterilize and/or stabilize UHMWPE [13-15], an investigation of optical properties (i.e., absorption coefficient $\mu \mathrm{a}$, scattering coefficients $\mu \mathrm{s}$ in pristine and irradiated UHMWPE $[10,16]$ and light distribution in pristine and irradiated UHMWPE [17-21]) needs to be conducted.

High power lasers have been used in the recent past for surface modifications of UHMWPE, e.g., Fernández-Pradas et al. [14] used a pulsed laser $(1027 \mathrm{~nm}, 450 \mathrm{fs} @ 1 \mathrm{kHz})$ for surface modification of UHMWPE, and found that pulses of $6 \mu \mathrm{J}$ has the highest ablation efficacy as compared to low energy pulses. Riveiro et al. [13] investigated laser irradiated UHMWPE samples and tried to optimize the process parameters for various pulsed lasers, i.e., $1064 \mathrm{~nm}, 532 \mathrm{~nm}$, and $355 \mathrm{~nm}$, to maximize the surface properties. In another study, Hussain et al. [22] carried out laser texturing on UHMWPE surface while using $1024 \mathrm{~nm}$ pulsed laser at various temperatures. More recently, Ullsperger et al. [23] utilized a high power pulsed laser to enhance the mechanical properties of UHMWPE while fusing the UHMWPE particles with $500 \mathrm{fs}$ laser pulses of $1030 \mathrm{~nm}$. In this study, they were able to achieve better values of ultimate tensile strength by controlling the pulse energy and repetition rate. Although above mentioned studies are important for surface modifications/texturing of UHMWPE, the choice of laser wavelength has been done without considering the fundamentals of light-matter interaction, i.e., the optical properties and light distribution characteristics of UHMWPE.

A significant amount of work has been done to investigate the optical properties and distribution of light in soft materials and various tissues [24-26]; however, UHMWPE's optical behavior has seldom been investigated. In research, Hamna et al. [20] highlighted the effects of radiation on spectroscopic properties, direct/indirect transition, and absorption behavior for e-beam irradiated UHMWPE. In another study, Asif et al. [27] concluded the anisotropic nature of UHMWPE in the UV-VIS region and confirmed the forwarded scattering nature of UHMWPE for UV-VIS light. Furthermore, the literature reveals a linear dependence between direct Urbach energy $\left(E_{\mathfrak{u}}\right)$ band gaps and absorbed dose [28]. More recently, Noor Us Saba et al. [29] studied the light distribution in UHMWPE for $300 \mathrm{~nm}$ and $800 \mathrm{~nm}$ and found that photons with low energy/higher wavelengths penetrate by a greater distance. The results reported in this study confirmed the fact that light of longer wavelength was suitable for UHMWPE bulk modification and/or treatment. Although the results reported by [29] were hopeful, unfortunately these were only for pristine UHMWPE.

The main objective of this study is to figure out the distribution of light so that it can be used to modfiy and/or stablize the irradiated UHMWPE. It is well established that radiation induces free radicals that are trapped within the UHMWPE matrix and can be eliminated via enhancing polyethylene long chain moblity and treating the irradiated components of UHMWPE with light of suitable wavelength and energy. However, knowledge about the distribution of light within the matrix of UHMWPE is required in order to achieve the aformentioned objetive. Therefore, this particular study is aimed at investigating the effect of radiation treatment on the measured values of diffuse reflectance, transmittance, and absorption of light from UHWMPE from $600 \mathrm{~nm}$ to $800 \mathrm{~nm}$. The choice of light wavelengths is because of the proposed study theme where utilization of light is required for bulk treatment of UHMWPE. The optical properties, including the absorption coefficient $(\mu \mathrm{a})$, scattering coefficients $(\mu \mathrm{s})$, total attenuation coefficients $(\mu \mathrm{t})$, and effective attenuation 
coefficients ( $\mu$ eff), were measured and then simulated to explore the effect of radiation on the light distribution.

\section{Materials and Methods}

\subsection{Material and Sample Preparation}

Medical grade UHMWPE powder (having molecular weight 3-6 million g/mol) purchased from Sigma Aldrich ${ }^{\circledR}$ Saint Louis, MO, USA (Product Number: 434264 CAS Number: 9002-88-4 MDL: MFCD00084423 Formula: $\mathrm{C}_{2} \mathrm{H}_{4}$ ) was used in this study. Samples were molded in the form of thin sheets by using an automated hot press. UHMWPE powder pressing was done at 200 bars with a holding time of $12-15$ min at $140{ }^{\circ} \mathrm{C}, 160{ }^{\circ} \mathrm{C}$, and $190{ }^{\circ} \mathrm{C}$, respectively. During the process of molding, the cool-down and ramp-up rate was set to $10^{\circ} \mathrm{C} / \mathrm{min}$. After preparation, the thickness was measured and it was found that each sheet has a thickness equal to $500 \pm 10 \mu \mathrm{m}$. Before measuring the thickness, each sheet surface was wiped off with acetone to remove the impurities.

\subsection{Sample Irradiation}

After the preparation of sheets, samples were divided into three groups. One was kept on the shelf as control and the other two sheets were sent for irradiation. Irradiation services were carried out (on payment) at Pakistan Radiation Services (PARS), Lahore while using the Co-60 source for $30 \mathrm{kGy}$ and $100 \mathrm{kGy}$ of gamma dose at a constant dose-rate of $1.02 \mathrm{kGy} / \mathrm{h}$ in open air at room temperature. After radiation treatment, the sheets were labeled P-0, P-30, and P-100. It is worth mentioning here that the dimensions of each sheet sent for irradiation were $10 \mathrm{~cm} \times 10 \mathrm{~cm} \times 500 \mu \mathrm{m}$, which was then cut to make three or four samples for testing. The sample codes mentioned above were used throughout the manuscript for explaining the results. The radiation facility used is used for providing sterilization services to food and medical devices and is constantly monitored by the Pakistan Nuclear Regulatory Agency (PNRA) for its reliability, safety, and environmental homogeneity.

\subsection{Measurements of $R_{d} \mathcal{E} T_{d}$}

A diffuse reflectance spectrometer (DRS) setup (UV/VIS/NIR spectrometer Lamda 950, integrated sphere $150 \mathrm{~mm}$ ) purchased from PerkinElmer Life and Analytical Sciences (710 Bridgeport Avenue Shelton, CT 06484-4794, Waltham, MA, USA), equipped with an integrated sphere $150 \mathrm{~mm}$ with the spectral range from $250 \mathrm{~nm}$ to $1000 \mathrm{~nm}$, was used for testing the samples. The reflectance and transmittance measurements were carried out at room temperature, i.e., $25^{\circ} \mathrm{C}$. Three or four readings were taken for each measurement and the average for each sample was then plotted as a function of wavelength and absorbed dose. The standard deviation for each measured data was negligible, i.e., $\leq 3 \%$.

\section{Results and Discussion}

\subsection{Effect of Radiation on Measurable}

This research is aimed at investigating the light distribution in pristine and gammairradiated UHMWPE. To investigate this, diffuse reflectance and transmittance from $600 \mathrm{~nm}$ to $800 \mathrm{~nm}$ were measured, and the Kubleka-Munk model (KMM) was employed to extract the optical properties. The efficacy of the method for extracting the optical parameters, i.e., scattering coefficients $\left(\mu_{\mathrm{s}}\right)$ and absorption coefficient $\left(\mu_{\mathrm{a}}\right)$ in $\mathrm{cm}^{-1}$ was then validated theoretically with the Monte Carlo simulation. After validation, the obtained parameters were then used as inputs for obtaining the detailed picture of light distribution in pristine and irradiated UHMWPE.

Shown in Figure 1 are the variations of diffuse reflectance as a function of wavelengths for pristine, $30 \mathrm{kGy}$, and $100 \mathrm{kGy}$ irradiated samples, respectively. The following trends are evident from the figure:

- Diffuse reflectance decreases as a function of incident wavelength for all samples, whether it is irradiated or un-irradiated.

- The amount of reflectance is higher in the visible range and lower in the near-infrared region. 
- The amount of diffused reflected light is significantly reduced for $30 \mathrm{kGy}$ and $100 \mathrm{kGy}$ irradiated samples.

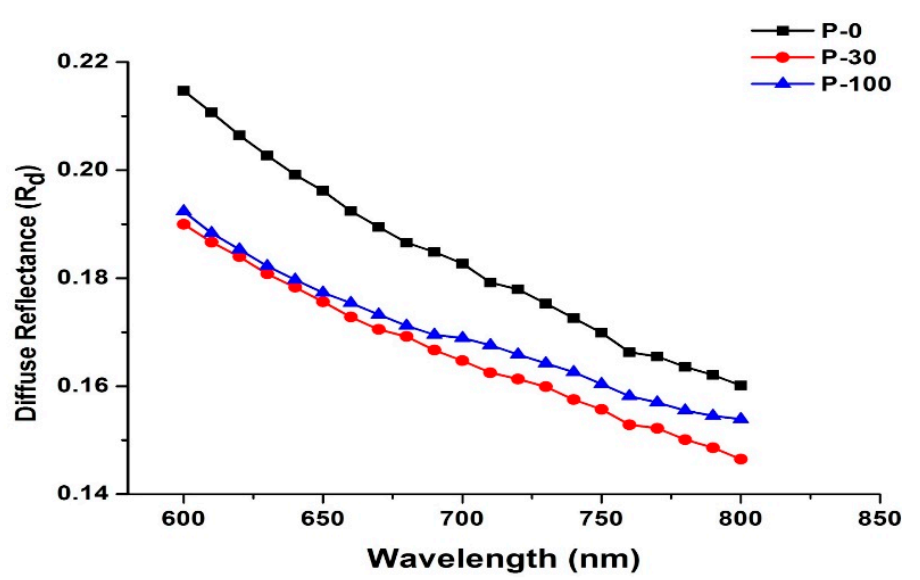

Figure 1. Experimental values of diffuse reflectance over the spectral range of wavelength from $600 \mathrm{~nm}$ to $800 \mathrm{~nm}$.

The factors responsible for reflectance of incident light from highly scattering materials like UHMWPE are:

- Surface roughness of the sample

- Refractive index mismatch

- Sample thickness

The diffusively reflected light is a combination of numerous refractions, reflections, and diffractions before being detected as diffuse reflectance. Furthermore, it also includes specular reflectance [29] in addition to the abovementioned contributions [30]. It is well established that irradiating UHMWPE in the open air results in an increase in polyethylene crystallinity [31-34]. Moreover, results reported in the literature [35] have shown that an increase in the crystallinity of the polymer composites leads to an increase in optical absorption, which is the main reason for the increase in absorption and lower value of diffuse reflectance for irradiated samples at each wavelength of interest during this study. The scattering of incident light from radiation-induced trapped free radicals within the UHMWPE matrix might be responsible for slightly higher values of $R_{d}$ for the $100 \mathrm{kGy}$ sample as the concentration of trapped free radicals is higher [36]. The higher values of $R_{d}$ (as shown in Figure 1), larger penetration depth at longer wavelength, and larger concentration of free radicals for $100 \mathrm{kGy}$ samples also support this argument [37-39].

The $T_{d}$ trends differ from the $R_{d}$ trends reported above in two respects: (1) $T_{d}$ increases as a function of incident wavelength for all samples, whether irradiated or not; and (2) $T_{d}$ values for $100 \mathrm{kGy}$ irradiated sample is higher when compared with $30 \mathrm{kGy}$ irradiated samples (see Figure 2). The measured values of diffuse transmittance depends on light photons that are scattered in the forward direction and the forward-directed scattering nature (in the optical window) of UHMWPE has been well documented in recent years [27]. Therefore, the increase in $T_{d}$ as a function of incident wavelength is quite understandable; however, the behavior $\mathrm{T}_{\mathrm{d}}$ for $100 \mathrm{kGy}$ irradiated (highlighted above) is because of higher values of cross-linking networks for the $100 \mathrm{kGy}$ irradiated samples [40]. It is well documented that the cross-linking networks within the UHMWPE matrix are responsible for aligning the randomly distributed crystalline lamellae in the amorphous slough of $\mathrm{CH}_{2}$ units [17,41-44]. Therefore, the $100 \mathrm{kGy}$ irradiated sample is more oriented and transparent as compared to the $30 \mathrm{kGy}$ one, which is observed experimentally (see Figure 2). 


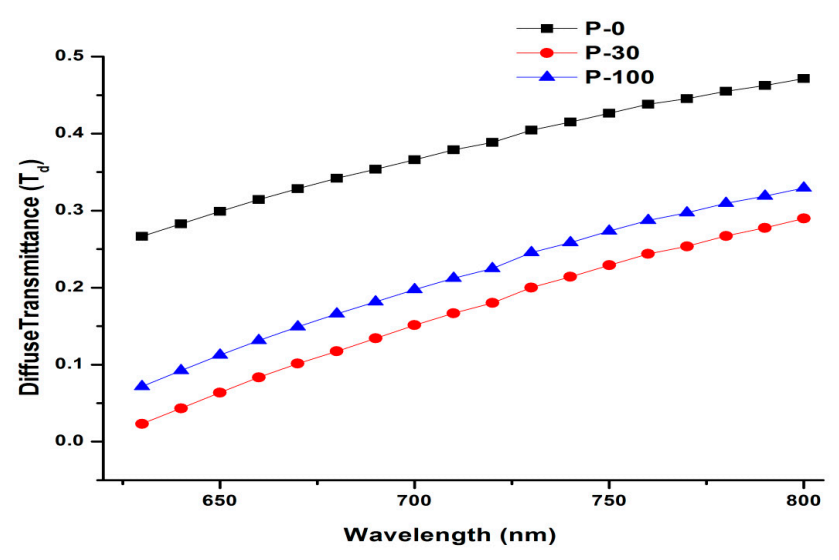

Figure 2. Variation in diffuse transmittance by increasing the wavelength from $600 \mathrm{~nm}$ to $800 \mathrm{~nm}$ with radiation dosage $0,30 \mathrm{kGy}$, and $100 \mathrm{kGy}$.

The trends for absorption obtained from the values of transmittance and reflectance are shown in Figure 3. The absorption values at lower wavelengths are higher as compared to higher wavelengths, and there is a significant increase in absorption values at each wavelength after irradiation. The increase in absorption is higher for the $30 \mathrm{kGy}$ samples compared to the $100 \mathrm{kGy}$ samples. This increase in absorption due to radiation-induced treatment is responsible for the reorganization of the chain by scission due to irradiation because of higher oxidative damage in the $30 \mathrm{kGy}$ sample $[28,31]$ is one of the major factors responsible for the observed higher values of absorption for the $30 \mathrm{kGy}$ sample. Furthermore, the role of higher crosslinking yield in the $100 \mathrm{kGy}$ irradiated sample (which is responsible for aligning and making the polymer matrix more oriented and transparent in a given wavelength range of interest) cannot be ruled out here.

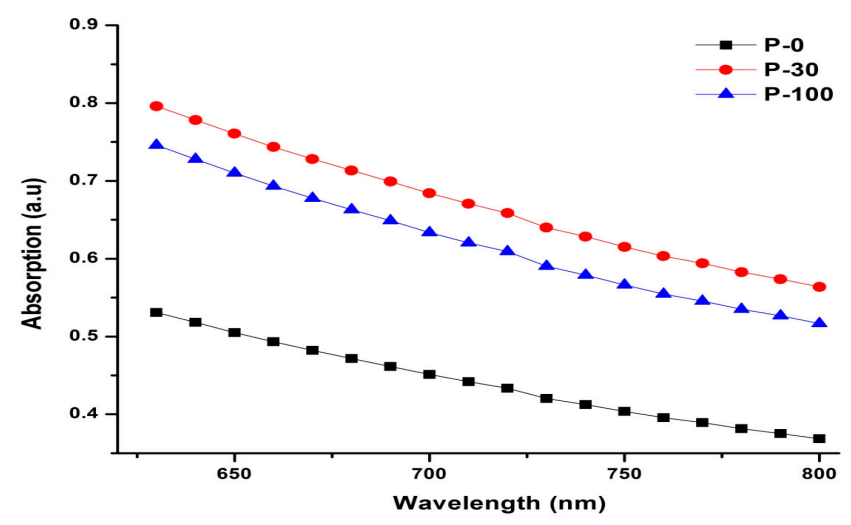

Figure 3. Experimentally measured values of absorption from UHMWPE sample over the spectral range of interest, i.e., $600 \mathrm{~nm}$ to $800 \mathrm{~nm}$.

\subsection{Extraction of Optical Properties}

In the study, the DRS approach was implemented for the extraction of optical properties from measurements because of its simplicity and feasibility for the aforementioned purpose. DRS has the potential to quantify scattering and absorption properties related to highly scattering materials like UHMWPE [29]. To extract UHMWPE optical characteristics, i.e., absorption coefficient $\mu_{\mathrm{a}}$ and $\mu_{\mathrm{s}}$ for each sample used in this study, the two flux Kubleka-Munk model (KMM) is utilized, which utilizes the measured values of $R_{d}$ and $T_{d}$ and sample thickness. The following equations are used to figure out the optical characteristics of pristine and irradiated UHMWPE

$$
\mathrm{S}=\frac{1}{\mathrm{yt}}\left[\frac{1-\mathrm{R}_{\mathrm{d}}(\mathrm{x}-\mathrm{y})}{\mathrm{T}_{\mathrm{d}}}\right]
$$




$$
\begin{gathered}
\mu_{\mathrm{a}}=\frac{\mathrm{K}}{2}, \quad \mu_{\mathrm{s}}=\frac{\left(4 \mathrm{~S}+\mu_{\mathrm{a}}\right)}{3(1-\mathrm{g})}, \quad \mathrm{K}=\mathrm{S}(\mathrm{x}-1) \\
\mathrm{x}=\frac{\left[1-\mathrm{T}_{\mathrm{d}}{ }^{2}+\mathrm{R}_{\mathrm{d}}^{2}\right]}{2 \mathrm{R}_{\mathrm{d}}}, \mathrm{y}=\sqrt{\mathrm{x}^{2}-1}
\end{gathered}
$$

where

- $\mathrm{K}$ is the flux loss per absorption per unit length

- $\mathrm{S}$ is the scattering per unit length

- $R_{d}$ is the measured value of diffuse reflectance

- $\mathrm{T}_{\mathrm{d}}$ is the measured value of diffuse transmittance

- $\quad t$ is the sample thickness

- $\mathrm{g}$ is the anisotropy factor and its value is taken as 0.9 due to the forwarded directed scattering nature of UHMWPE $[27,28]$

\subsection{Effect of Radiations on Extracted Optical Properties}

The extracted optical properties for pristine, $30 \mathrm{kGy}$, and $100 \mathrm{kGy}$ samples corresponding to each incident wavelength are tabulated in Table 1 . The following trends of absorption coefficients $\left(\mu_{\mathrm{a}}\right)$ and scattering coefficients $\left(\mu_{\mathrm{s}}\right)$ are obvious as a function of the increase in incident wavelength and absorbed dose.

\begin{tabular}{|c|c|c|c|c|c|c|c|c|c|}
\hline \multirow{2}{*}{$\lambda(\mathrm{nm})$} & \multicolumn{3}{|c|}{$\begin{array}{c}\text { Absorption } \\
\text { Coefficient } \mu_{\mathrm{a}}\left(\mathrm{cm}^{-1}\right)\end{array}$} & \multicolumn{3}{|c|}{$\begin{array}{l}\text { Scattering Coefficient } \\
\mu_{\mathrm{s}}\left(\mathrm{cm}^{-1)}\right.\end{array}$} & \multicolumn{3}{|c|}{$\begin{array}{c}\text { Attenuation Coefficient } \\
\qquad \mu_{t}\left(\mathrm{~cm}^{-1}\right)\end{array}$} \\
\hline & P-0 & P-30 & P-100 & P-0 & P-30 & P-100 & P-0 & P-30 & P-100 \\
\hline 630 & 5.34 & 1.67 & 3.69 & 120.06 & 29.72 & 66.35 & 125.39 & 31.39 & 70.04 \\
\hline 640 & 5.44 & 1.84 & 4.48 & 121.17 & 32.28 & 79.63 & 126.61 & 34.12 & 84.11 \\
\hline 650 & 5.53 & 3.59 & 4.98 & 122.29 & 61.83 & 87.58 & 127.82 & 65.43 & 92.57 \\
\hline 660 & 5.62 & 4.50 & 5.30 & 122.92 & 76.30 & 92.61 & 128.54 & 80.81 & 97.92 \\
\hline 670 & 5.68 & 5.01 & 5.54 & 123.54 & 83.97 & 96.01 & 129.22 & 88.99 & 101.55 \\
\hline 680 & 5.74 & 5.32 & 5.73 & 124.04 & 88.71 & 98.45 & 129.79 & 94.03 & 104.18 \\
\hline 690 & 5.77 & 5.60 & 5.86 & 124.78 & 92.26 & 100.30 & 130.55 & 97.86 & 106.16 \\
\hline 700 & 5.80 & 5.80 & 5.95 & 125.38 & 94.93 & 102.11 & 131.19 & 100.74 & 108.07 \\
\hline 710 & 5.87 & 5.97 & 6.03 & 125.42 & 96.73 & 103.41 & 131.29 & 102.70 & 109.45 \\
\hline 720 & 5.88 & 6.07 & 6.11 & 126.03 & 98.11 & 104.23 & 131.91 & 104.18 & 110.34 \\
\hline 730 & 5.91 & 6.18 & 6.19 & 126.84 & 99.92 & 105.72 & 132.75 & 106.11 & 111.92 \\
\hline 740 & 5.95 & 6.29 & 6.25 & 126.85 & 100.57 & 106.35 & 132.81 & 106.86 & 112.60 \\
\hline 750 & 5.99 & 6.37 & 6.32 & 127.01 & 101.36 & 106.89 & 133.00 & 107.73 & 113.21 \\
\hline 760 & 6.04 & 6.46 & 6.38 & 126.73 & 101.62 & 107.24 & 132.77 & 108.09 & 113.63 \\
\hline 770 & 6.04 & 6.49 & 6.41 & 127.27 & 102.19 & 107.65 & 133.32 & 108.68 & 114.06 \\
\hline 780 & 6.06 & 6.55 & 6.44 & 127.60 & 102.48 & 108.08 & 133.66 & 109.038 & 114.53 \\
\hline 790 & 6.07 & 6.59 & 6.46 & 127.86 & 102.71 & 108.47 & 133.94 & 109.31 & 114.94 \\
\hline 800 & 6.09 & 6.65 & 6.47 & 128.02 & 102.78 & 109.11 & 134.12 & 109.43 & 115.59 \\
\hline
\end{tabular}

Table 1. Optical properties of UHMWPE samples at particular wavelengths.

- For an un-irradiated sample, $\mu_{\mathrm{a}}$ increases from $5.34 \mathrm{~cm}^{-1}$ to $6.09 \mathrm{~cm}^{-1}$, and $\mu_{\mathrm{s}}$ increases from $120.06 \mathrm{~cm}^{-1}$ to $128.02 \mathrm{~cm}^{-1}$ over the wavelength of interest, i.e., $630 \mathrm{~nm}$ to $800 \mathrm{~nm}$. The higher the incident wavelength, the longer the mean free path is before each interaction, so the abovementioned increase in $\mu_{\mathrm{a}}$ and $\mu_{\mathrm{s}}$ (as a function of wavelength) for the pristine sample is quite understandable. 
- There is a significant decrease in the coefficient $\left(\mu_{\mathrm{a}} \& \mu_{\mathrm{s}}\right)$ values from $630 \mathrm{~nm}$ to $700 \mathrm{~nm}$ for irradiated samples. Furthermore, it can be seen from the table that the decrease in coefficients for a $30 \mathrm{kGy}$ irradiated sample is higher as compared to a $100 \mathrm{kGy}$ irradiated one, which is due to greater oxidation damage $[17,37,38,40]$ for the $30 \mathrm{kGy}$ samples, as mentioned above.

- There is a slight increase in the values of $\mu_{\mathrm{a}}$ on moving from $700 \mathrm{~nm}$ to $800 \mathrm{~nm}$ for irradiated samples, which is attributed to the dominant scattering and small absorption of polyethylene on near IR and IR absorption [27,30]. The decrease in per unit scattering length, i.e., $\mu_{s}$ from $700-800 \mathrm{~nm}$ and the significant increase in $T_{d}$ for irradiated samples (see Table 1 and Figure 2) also supports this argument.

The decrease in absorption coefficient is dominant in the lower wavelength region for $30 \mathrm{kGy}$ irradiated samples (see Table 1). Similarly, there is a notable decrease in scattering coefficients, which is evidence of the fact that irradiating the samples is responsible for decreasing the absorption and scattering coefficients of the samples. However, an increase in the aforementioned light impeding events is higher for $30 \mathrm{kGy}$ samples as compared to the $100 \mathrm{kGy}$ one because of radiation induced free radical oxidation degradation [21,34].

The effective penetration depth ( $\delta$ in $\mathrm{mm}$ ) is a measure of how deep light or any electromagnetic radiation can penetrate. It is defined as the depth at which the intensity of the radiation inside the material falls to $1 / \mathrm{e}$ (about $37 \%$ ) of its original value at (or more properly, just beneath) the surface. The penetration depth is calculated as follows:

$$
\delta=1 / \mu \mathrm{eff}
$$

where:

$$
\mu_{e f f}=\sqrt{\mu_{a}+\mu_{s}(1-g)}
$$

Figure 4 represents the variation of $\delta$ as a function of incident wavelength and absorbed dose. The values for pristine UHMWPE are constant over the wavelength of interest; however, increases up to approximately $0.9 \mathrm{~mm}$ for the $100 \mathrm{kGy}$ irradiated sample and up to $2 \mathrm{~mm}$ for the $30 \mathrm{kGy}$ sample. As the attenuation coefficient ' $\mu_{\mathrm{t}}$ ' (sum of absorption and scattering coefficients) is the major responsible factor in reducing the intensity of the incident beam. Therefore, the increase in the values of penetration depth $\delta$ for irradiated samples (more specifically for the $30 \mathrm{kGy}$ sample) (see Figure 4) is quite justified and understandable.

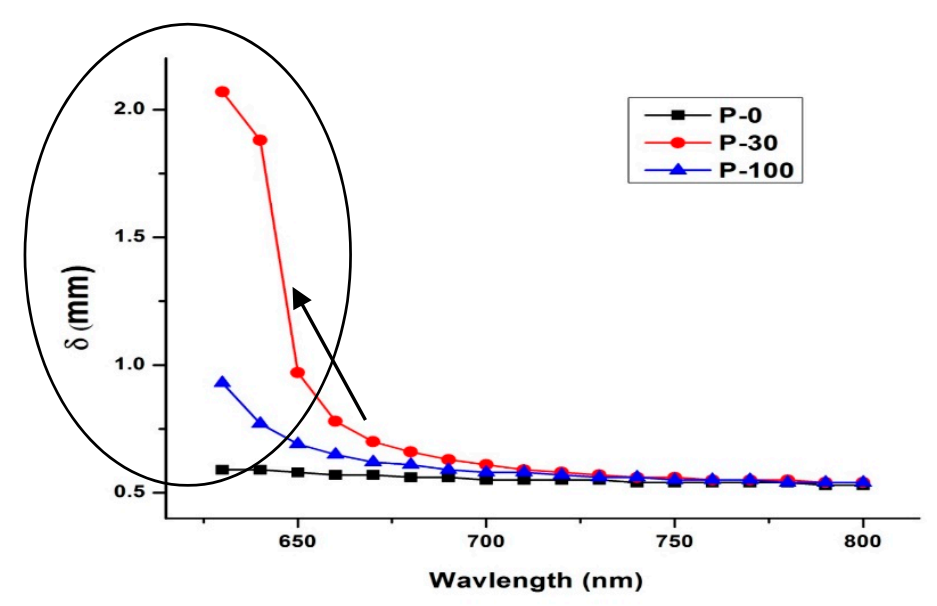

Figure 4. Penetration depth for the sample UHMWPE over the wavelength of interest from $600 \mathrm{~nm}$ to $800 \mathrm{~nm}$.

\subsection{Theoretical Validation of Extracted Optical Properties}

Theoretical validation of the extracted optical properties is performed by using the output of the KMM model as an input of the MCML model, which is the general- 
purpose Monte Carlo-based code to simulate the light propagation through turbid media. The Monte Carlo-based simulation program, MCML, for the infinitely narrow beam is available at the website https:/ / omlc.org/software/mc/ (assessed on 23 November 2019) [45]. This code is used in this study to simulate the light by getting experimental results from the KMM model. The code simulates the light transport in the xyz-planes while considering the sample surfaces the $x$ - and $y$-axes, and depth z-axis [46,47].

In order to simulate a normal incident photon beam, the cosines direction are first defined as $r_{x}=0, r_{y}=0, r_{z}=1$ along $x-y$ emission plane with polar angle $\theta$ directed normal to the surface. To define each photon emission, an emission cone having azimuthal angle $\varphi$ is used. The four-dimensional functions that are recorded in the course of this study are absorption, transmittance, diffusion, and reflectance. The sample thickness that is used as an input is $0.05 \mathrm{~cm}$, i.e., similar to that taken in the experimental measurements. The direction and emission position are split into 200 bins of $50 \times 10^{-4} \mathrm{~cm}$ each on the $x-y$ plane, having 30 bins regarding $\theta \in[0, \pi / 2]$ and 48 bins for $\phi \in[0,2 \pi]$. For each run, $5 \times 10^{8}$ photons (each with unit weight) are used for the calculation of absorption, transmittance, and reflectance. For validation, the theoretical results are compared with the experimental ones and are shown in Figure 5 as a radar plot.

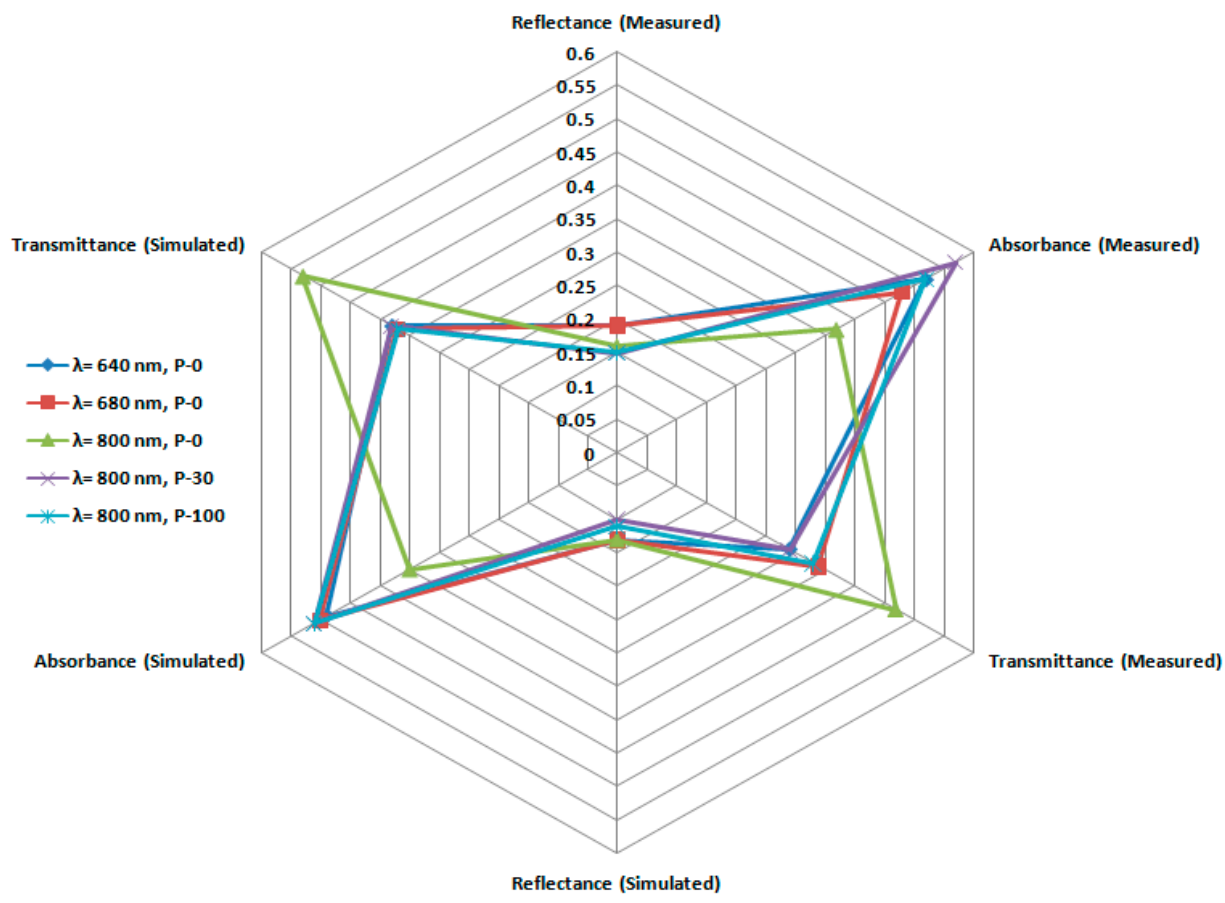

Figure 5. Radar Plot for representing the theoretical and experimental data validation.

The simulated physical properties (transmittance, reflectance, and absorbance) at $800 \mathrm{~nm}$ for pristine, $30 \mathrm{kGy}$, and $100 \mathrm{kGy}$ irradiated samples are then plotted against the measured ones on a radar plot as shown in Figure 5. The symmetry of the trend about the central axis of the plot is evident (see Figure 5). This confirms the excellent correspondence between experimental and simulated results with a relative difference of less than $5 \%$ among the experimental and theoretical values.

\subsection{Effect of Radiation on Light Distribution}

After being confident that the extracted optical parameters are correct and that the theoretical results of reflectance, transmittance, and absorbance generated (with these extracted optical properties as input) with Monte Carlo model for light transport from turbid media are in good agreement with the measured values, the photon distribution within the UHMWPE is modeled. The results of photon absorption as a function of $\mathrm{z}$ and $\mathrm{r}$ at $800 \mathrm{~nm}$ for pristine, $30 \mathrm{kGy}$ irradiated, $100 \mathrm{kGy}$ irradiated UHMWPE are shown in 
Figure 6. The noteworthy trends in the above figure are the increase in penetration depth and photon absorption per unit area with irradiation. To have a clearer insight, one can see the end of the light blue colored contour, which ends at $0.03 \mathrm{~cm}$ for pristine UHMWPE samples at $0.32 \mathrm{~cm}$ for $30 \mathrm{kGy}$ irradiated samples, and at $0.034 \mathrm{~cm}$ for $100 \mathrm{kGy}$ irradiated samples. Furthermore, the absorbed number of photons in the first contour for P-0, P-30, and P-100 are $4.70 \times 10^{5} \mathrm{~cm}^{-2}, 4.98 \times 10^{5} \mathrm{~cm}^{-2}$, and $5.12 \times 10^{5} \mathrm{~cm}^{-2}$, respectively. The effect of radiation on the transport albedo, which is the ratio of scattering coefficients to the attenuation coefficients, can be used to explain the photon distribution characteristics of UHMWPE. The values of transport albedo vary from 0 to 1 . The transport albedo $=0$ means that no light will pass through the sample while transport albedo $=1$ means the incident light passes through the sample without any absorption. It can be seen from Table 1 that transport albedo is 0.9545 for $\mathrm{P}-0$ and its value reduces to 0.9392 with irradiation, which is evidence of the fact that photon distribution per unit area, i.e., number of photon $/ \mathrm{cm}^{2}$ is higher for irradiated samples. The photon distribution representations shown in Figure 6, i.e., the plots of absorption as a function of wavelength and radiation, are in favor of our argument that transport albedo is an important factor to consider when using light as an alternative for UHMWPE modification and/or stabilization.

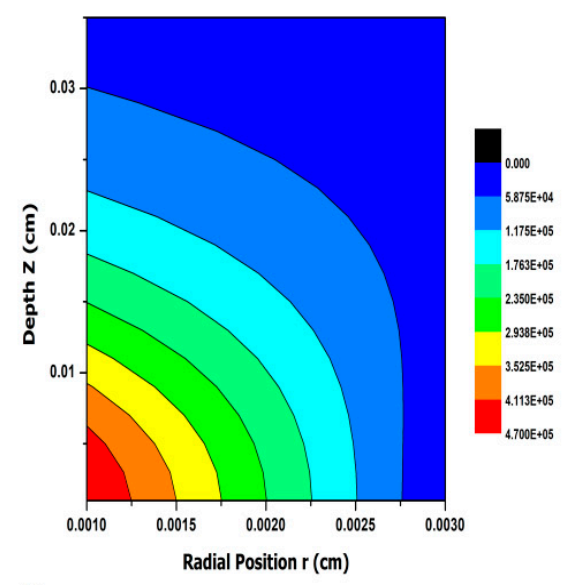

(a)

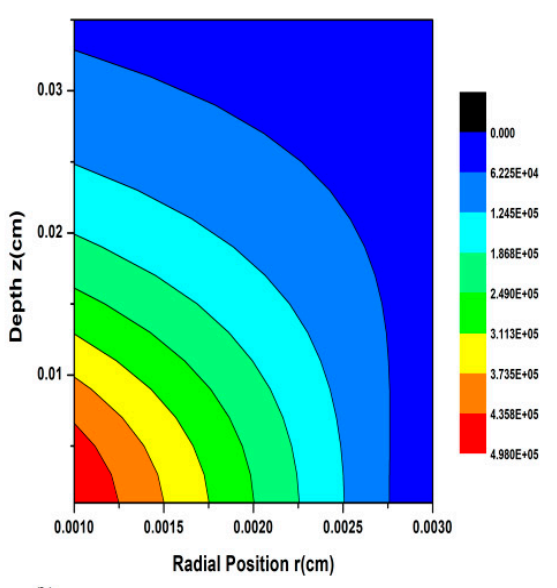

(b)

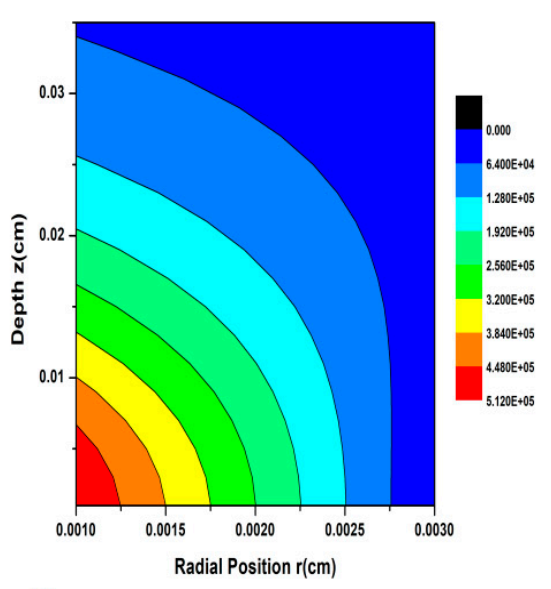

(c)

Figure 6. Photon distribution representation as a function of depth (z) and radial position (r) at $800 \mathrm{~nm}$ for (a) pristine UHMWPE (b) 30 kGy irradiated UHMWPE, and (c) 100 kGy irradiated UHMWPE.

\section{Conclusions}

In this study, the effects of gamma irradiation and absorbed dose on the optical properties (absorption and scattering coefficients) of UHMWPE from $600 \mathrm{~nm}$ to $800 \mathrm{~nm}$ are explored. The optical characteristics of pristine and gamma irradiated UHMWPE sample were extracted using the KMM model in conjugation with measured values of diffuse reflectance and transmittance. The results reveal a significant decrease in coefficient $\left(\mu_{\mathrm{a}} \& \mu_{\mathrm{s}}\right)$ values for irradiated samples at lower wavelengths, i.e., from $630 \mathrm{~nm}$ to $700 \mathrm{~nm}$. This decrease in coefficients for the $30 \mathrm{kGy}$ irradiated sample is higher as compared to the $100 \mathrm{kGy}$ irradiated one and is attributed to the higher oxidation damage of UHMWPE at this dose value. The slight increase in the values of scattering coefficients $\mu \mathrm{a}$ on moving from $700 \mathrm{~nm}$ to $800 \mathrm{~nm}$ for irradiated samples is attributed to dominant scattering and small absorption of polyethylene on near IR and IR absorption. Furthermore, light distribution at $800 \mathrm{~nm}$ is modelled for pristine, $30 \mathrm{kGy}$ and $100 \mathrm{kGy}$ gamma-irradiated samples using Monte Carlo methods. The extracted scattering and absorption coefficients are used as inputs for simulating the $5 \times 108$ photons (each with unit weight) for each run. The results reveal an increase in the penetration depth and photon absorption per unit area with irradiation, which is attributed to a decrease in transport albedo, i.e., the ratio of scattering coefficients to the attenuation coefficients with irradiation. We thus conclude that transport 
albedo is the prime and most important factor to be considered before using a suitable light wavelength as an alternative for the modification and/or stabilization of UHMWPE.

Author Contributions: Supervision, A.R., M.S., and H.A.; data collection and analysis, S.H.S., M.S.M., and A.G.; writing-original draft, A.R., H.A., A.G., M.S., S.H.S., and M.S.M. All authors have read and agreed to the published version of the manuscript.

Funding: This research received no external funding.

Institutional Review Board Statement: Not applicable.

Informed Consent Statement: Not applicable.

Data Availability Statement: Data will be provided on demand.

Acknowledgments: The authors acknowledge the moral support provided by the King Abdulaziz 439 University, Jeddah 21589, Saudi Arabia to accomplish this research. The technical support from UET Taxila, Pakistan for providing experimental data where required is also acknowledged here.

Conflicts of Interest: The authors declare no conflict of interest associated with this research article.

\section{References}

1. Barani, M.; Mukhtar, M.; Rahdar, A.; Sargazi, S.; Pandey, S.; Kang, M. Recent Advances in nanotechnology-based diagnosis and treatments of human osteosarcoma. Biosensors 2021, 11, 55. [CrossRef] [PubMed]

2. Arshad, R.; Tabish, T.A.; Kiani, M.H.; Ibrahim, I.M.; Shahnaz, G.; Rahdar, A.; Kang, M.; Pandey, S. A hyaluronic acid functionalized self-nano-emulsifying drug delivery system (SNEDDS) for enhancement in ciprofloxacin targeted delivery against intracellular infection. Nanomaterials 2021, 11, 1086. [CrossRef] [PubMed]

3. Sabir, F.; Zeeshan, M.; Laraib, U.; Barani, M.; Rahdar, A.; Cucchiarini, M.; Pandey, S. DNA based and stimuli-responsive smart nanocarrier for diagnosis and treatment of cancer: Applications and challenges. Cancers 2021, 13, 3396. [CrossRef] [PubMed]

4. Calcagno, L.; Compagnini, G.; Foti, G. Structural modification of polymer films by ion irradiation. Nucl. Instrum. Methods Phys. Res. Sect. B Beam Interact. Mater. At. 1992, 65, 413-422. [CrossRef]

5. Fink, D.; Chung, W.; Klett, R.; Schmoldt, A.; Cardoso, J.; Montiel, R.; Vazquez, M.H.; Wang, L.; Hosoi, F.; Omichi, H.; et al. Carbonaceous clusters in irradiated polymers as revealed by UV-Vis spectrometry. Radiat. Eff. Defects Solids 1995, 133, 193-208. [CrossRef]

6. Mishra, R.; Tripathy, S.P.; Dwivedi, K.K.; Khathing, D.T.; Ghosh, S.; Müller, M.; Fink, D. Electron induced modification in poly (ethylene terephthalate). Radiat. Eff. Defects Solids 2001, 153, 257-269. [CrossRef]

7. Mishra, R.; Tripathy, S.P.; Sinha, D.; Dwivedi, K.K.; Ghosh, S.; Khathing, D.T.; Müller, M.; Fink, D.; Chung, W.H. Optical and electrical properties of some electron and proton irradiated polymers. Nucl. Instrum. Methods Phys. Res. Sect. B Beam Interact. Mater. At. 2000, 168, 59-64. [CrossRef]

8. Phukan, T.; Kanjilal, D.; Goswami, T.D.; Das, H.L. Dielectric response of heavy ion irradiated PADC track detector. Nucl. Instrum. Methods Phys. Res. Sect. B Beam Interact. Mater. At. 1999, 155, 116-119. [CrossRef]

9. Pivin, J.C. Hardening and embrittlement of polyimides by ion implantation. Nucl. Instrum. Methods Phys. Res. Sect. B Beam Interact. Mater. At. 1994, 84, 484-490. [CrossRef]

10. Sinha, D.; Dwivedi, K. Modifications of radiation detection response of PADC track detectors by photons. Radiat. Phys. Chem. 1998, 53, 99-105. [CrossRef]

11. Tidjani, A.; Watanabe, Y. Gamma-oxidation of linear low-density polyethylene: The dose-rate effect of irradiation on chemical and physical modifications. J. Polym. Sci. Part A Polym. Chem. 1995, 33, 1455-1460. [CrossRef]

12. Tamai, T.; Watanabe, M.; Kobayashi, Y.; Kobata, J.; Nakahara, Y.; Yajima, S. Surface modification of polyethylene naphthalate substrates by ultraviolet light-irradiation and assembling multilayers and their application in electroless deposition: The chemical and physical properties of the stratified structure. Colloids Surf. A Physicochem. Eng. Asp. 2019, 575, 230-236. [CrossRef]

13. Riveiro, A.; Soto, R.; del Val, J.; Comesaña, R.; Boutinguiza, M.; Quintero, F.; Lusquiños, F.; Pou, J. Laser surface modification of ultra-high-molecular-weight polyethylene (UHMWPE) for biomedical applications. Appl. Surf. Sci. 2014, 302, 236-242. [CrossRef]

14. Fernández-Pradas, J.; Naranjo-León, S.; Morenza, J.; Serra, P. Surface modification of UHMWPE with infrared femtosecond laser. Appl. Surf. Sci. 2012, 258, 9256-9259. [CrossRef]

15. Xu, Z.; Xu, G.; Han, B.; Wang, K.; Ge, H.; An, B.; Ju, D.; Chai, M.; Li, L.; Zhou, W. Fabrication and sterilization characteristics of visible light photocatalyst of $\mathrm{CuO} / \mathrm{ZrO} 2 / \mathrm{CB} / \mathrm{Coal}-\mathrm{Tar}-P i t c h-S A C$. Coatings 2021, 11, 816. [CrossRef]

16. Singh, S.; Prasher, S. The etching and structural studies of gamma irradiated induced effects in CR-39 plastic track recorder. Nucl. Instrum. Methods Phys. Res. Sect. B Beam Interact. Mater. At. 2004, 222, 518-524. [CrossRef]

17. Mehmood, M.S.; Jahan, M.S.; Yasin, T.; Tariq, M.; Choudhry, M.A.; Ikram, M. On the structural analysis of-ray induced primary free radicals in UHMWPE and vitamin E stabilized UHMWPE by ESR spectroscopy. J. Spectrosc. 2015, 2015, 653853. [CrossRef]

18. Shafiq, M.; Mehmood, M.S.; Yasin, T. On the structural and physicochemical properties of gamma irradiated UHMWPE/silane hybrid. Mater. Chem. Phys. 2013, 143, 425-433. [CrossRef] 
19. Ghafoor, B.; Mehmood, M.S.; Shahid, U.; Baluch, M.A.; Yasin, T. Influence of $\gamma$-ray modified MWCNTs on the structural and thermal properties of high-density polyethylene. Radiat. Phys. Chem. 2016, 125, 145-150. [CrossRef]

20. Khan, H.; Gahfoor, B.; Mehmood, M.S.; Ahmad, M.; Yasin, T.; Ikram, M. Spectroscopic and sub optical band gap properties of e-beam irradiated ultra-high molecular weight polyethylene. Radiat. Phys. Chem. 2015, 117, 172-177. [CrossRef]

21. Oral, E.; Beckos, C.G.; Muratoglu, O.K. Free radical elimination in irradiated UHMWPE through crystal mobility in phase transition to the hexagonal phase. Polymer 2008, 49, 4733-4739. [CrossRef] [PubMed]

22. Hussain, M.; Sufyan, M.; Abbas, N.; Ahmad, H.; Joyia, F.M.; Noman, M.; Ahsan, M.M.; Raza, M.N.; Razaq, A.; Zulqernain, M.; et al. Influence of laser processing conditions for texturing on ultra-high-molecular-weight-polyethylene (UHMWPE) surface. Case Stud. Therm. Eng. 2019, 14, 100491. [CrossRef]

23. Ullsperger, T.; Wencke, Y.L.; Yürekli, B.; Matthäus, G.; Rettenmayr, M.; Luinstra, G.A.; Nolte, S. Laser powder bed fusion of ultra-high molecular weight polyethylene (UHMWPE) using near-infrared ultrashort laser pulses. Mater. Des. 2021, $210,110048$. [CrossRef]

24. Dögnitz, N.; Wagnières, G. Determination of tissue optical properties by steady-state spatial frequency-domain reflectometry. Lasers Med. Sci. 1998, 13, 55-65. [CrossRef]

25. Kienle, A.; Lilge, L.; Patterson, M.S.; Hibst, R.; Steiner, R.; Wilson, B.C. Spatially resolved absolute diffuse reflectance measurements for noninvasive determination of the optical scattering and absorption coefficients of biological tissue. Appl. Opt. 1996, 35, 2304-2314. [CrossRef]

26. Nichols, M.G.; Hull, E.L.; Foster, T.H. Design and testing of a white-light, steady-state diffuse reflectance spectrometer for determination of optical properties of highly scattering systems. Appl. Opt. 1997, 36, 93-104. [CrossRef]

27. Kamal, A.; Bashir, M.; Firdous, S.; Yasin, T.; Tariq, M.; Ikram, M.; Mehmood, M.S. Optical properties of ultra-high molecular weight polyethylene (UHMWPE): A material of choice for total joint applications. Radiat. Phys. Chem. 2016, 118, 102-106. [CrossRef]

28. Mehmood, M.S.; Siddiqui, N.; Maqbool, S.A.; Baluch, M.A.; Mukhtar, S.S.; Yasin, T. Assessment of $\gamma$-sterilization and/or cross linking effects on orthopedic biomaterial using optical diffuse reflectance spectroscopy. Optik 2017, 144, 387-392. [CrossRef]

29. Mehmood, M.S.; Khan, Y.; Yasin, T. Optical properties of UHMWPE-II: Photon distributions studies using Monte Carlo simulation. Radiat. Phys. Chem. 2019, 158, 103-108. [CrossRef]

30. Bashir, M.; Mehmood, M.S.; Choudary, M.A.; Yasin, T.; Ahmad, I.; Tariq, M.; Noman-ul-Haq, M.; Asif, A.; Ikram, M. Analysis of pulse-laser-induced modifications on high-density polyethylene for laser processing of polyethylene. J. Russ. Laser Res. 2015, 36, 258-268. [CrossRef]

31. Mehmood, M.S.; Ullah, H.; Jahan, M.S.; Mishra, S.; Walters, B.M.; Ikram, M. The effect of high dose of gamma-irradiation on residual radicals concentration in ultra-high molecular weight polyethylene (UHMWPE) in the presence of vitamin E. Polym. Sci. Ser. A 2012, 54, 343-348. [CrossRef]

32. Mehmood, M.S.; Walters, B.M.; Yasin, T.; Ahmad, M.; Jahan, M.S.; Mishra, S.R.; Ikram, M. Correlation of residual radical's with three phase morphology of UHMWPE: Analysis for the dependence on heat involved during vitamin E diffusion. Eur. Polym. J. 2014, 53, 13-21. [CrossRef]

33. Mehmood, M.S.; Yasin, T.; Jahan, M.S.; Mishra, S.R.; Walters, B.M.; Ahmad, M.; Ikram, M. Assessment of residual radicals in $\gamma$-sterilized shelf-aged UHMWPE stabilized with $\alpha$-tocopherol. Polym. Degrad. Stab. 2013, 98, 1256-1263. [CrossRef]

34. Oral, E.; Malhi, A.S.; Muratoglu, O.K. Mechanisms of decrease in fatigue crack propagation resistance in irradiated and melted UHMWPE. Biomaterials 2006, 27, 917-925. [CrossRef]

35. Erb, T.; Zhokhavets, U.; Gobsch, G.; Raleva, S.; Stühn, B.; Schilinsky, P.; Waldauf, C.; Brabec, C.J. Correlation Between Structural and Optical Properties of Composite Polymer/Fullerene Films for Organic Solar Cells. Adv. Funct. Mater. 2005, 15, 1193-1196. [CrossRef]

36. Mehmood, M.S.; Thira, I.; Idris, A.; Yasin, T.; Ikram, M. UHMWPE band-gap properties-II: Effect of post e-beam irradiation real time shelf aging in air. Radiat. Phys. Chem. 2019, 159, 231-237. [CrossRef]

37. Gul, R.M.; McGarry, F.J.; Bragdon, C.R.; Muratoglu, O.K.; Harris, W.H. Effect of consolidation on adhesive and abrasive wear of ultra high molecular weight polyethylene. Biomaterials 2003, 24, 3193-3199. [CrossRef]

38. Buchanan, F.J.; Sim, B.; Downes, S. Influence of packaging conditions on the properties of gamma-irradiated UHMWPE following accelerated ageing and shelf ageing. Biomaterials 1999, 20, 823-837. [CrossRef]

39. Raghuvanshi, S.K.; Ahmad, B.; Siddhartha; Srivastava, A.K.; Krishna, J.B.M.; Wahab, M.A. Effect of gamma irradiation on the optical properties of UHMWPE (Ultra-high-molecular-weight-polyethylene) polymer. Nucl. Instrum. Methods Phys. Res. Sect. B Beam Interact. Mater. At. 2012, 271, 44-47. [CrossRef]

40. Buchanan, F.J.; White, J.R.; Sim, B.; Downes, S. The influence of gamma irradiation and aging on degradation mechanisms of ultra-high molecular weight polyethylene. J. Mater. Sci. Mater. Med. 2001, 12, 29-37. [CrossRef]

41. Mehmood, M.S.; Tabasam, M.; Ahmed, M.; Idris, A.; Yasin, T.; Ikram, M. Mueller matrix polarimetry for characterization of E-Beam irradiated Uhmwpe. Radiat. Phys. Chem. 2020, 166, 108503. [CrossRef]

42. Ogiwara, A.; Toda, M.; Ishido, J.; Watanabe, M.; Kakiuchida, H. Effects of a radiation dose in gamma-ray irradiation fields on holographic gratings formed by liquid crystal composites. OSA Contin. 2021, 4, 514-528. [CrossRef]

43. Forster, A.L.; Tsinas, Z.; Al-Sheikhly, M. Effect of Irradiation and Detection of Long-Lived Polyenyl Radicals in Highly Crystalline Ultra-High Molar Mass Polyethylene (UHMMPE) Fibers. Polymers 2019, 11, 924. [CrossRef] [PubMed] 
44. Zhao, Y.; Wang, M.; Tang, Z.; Wu, G. ESR study of free radicals in UHMW-PE fiber irradiated by gamma rays. Radiat. Phys. Chem. 2010, 79, 429-433. [CrossRef]

45. Lin, S.-P.; Wang, L.; Jacques, S.L.; Tittel, F.K. Measurement of tissue optical properties by the use of oblique-incidence optical fiber reflectometry. Appl. Opt. 1997, 36, 136-143. [CrossRef]

46. Wang, L.; Jacques, S.L.; Zheng, L. MCML-Monte Carlo modeling of light transport in multi-layered tissues. Comput. Methods Programs Biomed. 1995, 47, 131-146. [CrossRef]

47. Li, T.; Gong, H.; Luo, Q. Mcvm: Monte carlo modeling of photon migration in voxelized media. J. Innov. Opt. Health Sci. 2010, 03, 91-102. [CrossRef] 